\title{
Sodium hypochlorite accident resulting in life-threatening airway obstruction during root canal treatment: a case report
}

This article was published in the following Dove Press journal:

Clinical, Cosmetic and Investigational Dentistry

4 March 2015

Number of times this article has been viewed

\section{Maisa O Al-Sebaei' \\ Omar A Halabi² \\ Ibrahim E El-Hakim ${ }^{3}$}

'Department of Oral and Maxillofacial Surgery, King Abdulaziz University Faculty of Dentistry, Jeddah, Kingdom of Saudi Arabia; ${ }^{2}$ Saudi Board of Oral and Maxillofacial Surgery, Al-Noor Specialist Hospital, Makkah, Kingdom of Saudi Arabia; ${ }^{3}$ Department of Oral and Maxillofacial Surgery, Riyadh Colleges of Dentistry and Pharmacy, Riyadh, Kingdom of Saudi Arabia
Correspondence: Maisa O Al-Sebaei Department of Oral and Maxillofacial Surgery, King Abdulaziz University Faculty of Dentistry, PO Box 80209, Jeddah 21589, Kingdom of Saudi Arabia Email moalsebaei@kau.edu.sa
Aim: This case report describes a serious and life-threatening complication of the use of sodium hypochlorite as an irrigation solution in root canal therapy.

Summary: This case report describes a hypochlorite accident that occurred in a healthy 42-year-old female who was undergoing routine root canal therapy for the lower right central incisor (tooth \#41). After approximately 1 hour of irrigation with $3 \%$ sodium hypochlorite (for a total of $12 \mathrm{cc}$ ), the patient complained of severe pain and burning in the lip. The swelling progressed over the next 8 hours to involve the sublingual and submental fascial spaces with elevation of the tongue and resultant upper airway obstruction. The patient was intubated and remained on mechanical ventilation for 3 days. She recovered without any skin necrosis or nerve deficits.

Key learning points: This case report highlights the importance of carefully performing root canal irrigation with sodium hypochlorite to avoid complications. Careful injection without pressure, the use of proper rubber dam isolation, and the use of the endodontic needle are necessary to avoid this type of complication. Although it is a safe root canal irrigation solution, its use may lead to life-threatening complications. Early recognition and management of the untoward effects of sodium hypochlorite are vital for the patient's safety.

Keywords: complications of root canal, facial edema, root canal irrigation, root canal therapy, sodium hypochlorite, upper airway obstruction

\section{Background}

Although sodium hypochlorite $(\mathrm{NaOCl})$ is considered the most effective, inexpensive, and readily available agent for root canal irrigation because of its tissue-dissolving, antibacterial, and lubrication properties, ${ }^{1}$ it is toxic to vital tissues and able to corrode metals, and damage to clothing and significant injuries to the eyes, skin, or oral mucosa can be caused by its accidental spillage. Some endodontists believe that deep delivery of the irrigation solution into root canals results in a more effective removal of debris, ${ }^{2}$ but the disadvantage of this method of delivery may be an increased apical extrusion. ${ }^{3}$ The irrigation solution may be extruded from the apical foramen during root canal preparation, as reported by Brown et al. ${ }^{3}$

An $\mathrm{NaOCl}$ accident occurs when there is extravasation of this irrigation solution beyond the apex, leading to tissue necrosis. ${ }^{4,5}$ This manifests as severe pain, burning, rapid tissue swelling, and bleeding from the periapical tissue. ${ }^{4,6,7}$

We present a life-threatening case that rapidly developed following the use of $\mathrm{NaOCl}$ as an endodontic irrigation solution to result in swelling of the floor of the mouth and a compromised airway that necessitated intubation for 3 days. 


\section{Case presentation}

A 42-year-old female who was apparently healthy with no known allergies presented to the undergraduate clinic at the dental school of King Abdulaziz University, Jeddah, Kingdom of Saudi Arabia, for endodontic treatment of her lower right central incisor (tooth \#41). The patient was given an inferior alveolar nerve block, a rubber dam was applied, endodontic access was achieved, and the pulp was extirpated. The student irrigated the canal using a total of $12 \mathrm{cc}$ of $3 \%$ $\mathrm{NaOCl}$. During irrigation, the student noticed increased bleeding from the canal, and the instructor advised her to continue irrigation to stop the bleeding.

The patient reported severe pain and a burning sensation, and the student immediately stopped the treatment and removed the rubber dam, at which point she noticed extensive swelling of the lower lip and chin related to the treated tooth (Figure 1). The emergency response team in the dental school was summoned and, upon arrival, they found that the patient's vital signs were stable and her oxygen saturation was $100 \%$. An intravenous line was started immediately, and a dose of $100 \mathrm{mg}$ of hydrocortisone was administered through the intravenous line. The patient was transferred to the emergency department for observation.

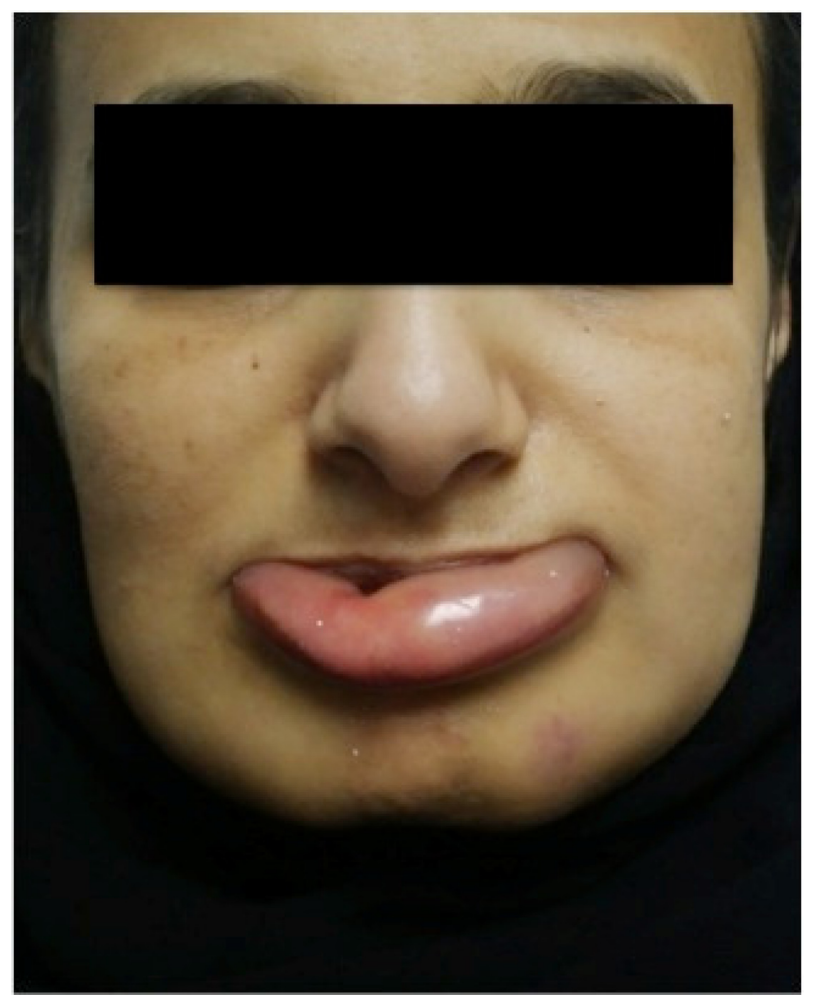

Figure I Swelling of the lower lip and chin after I hour of irrigation with sodium hypochlorite.
The swelling in the chin and sublingual area continued to progress rapidly during the next 4 hours, involving the lips and the submental and sublingual spaces and resulting in elevation of the floor of the mouth. At that point, the patient started to exhibit signs of upper airway obstruction, with stridor, labored breathing, and declining oxygen saturation.

The patient was transferred to the intensive care unit (ICU), where a decision was made to intubate her using an oral endotracheal tube, which was inserted without difficulty, and the patient was placed on a mechanical ventilator. During her stay in the ICU, she was treated with $1,000 \mathrm{mg}$ of cefazolin and $8 \mathrm{mg}$ of dexamethasone every 8 hours. She remained intubated for 72 hours, during which the swelling started to slowly decline and the floor of the mouth became soft and nonraised (Figure 2).

The patient was extubated after exhibiting positive cuffleak test results and other ICU extubation criteria. At that time, intraoral examination revealed a $2 \mathrm{~cm} \times 1 \mathrm{~cm}$ ulcer in the lower anterior vestibule, extending in depth to the bone (Figure 3). The patient denied any paresthesia or altered sensation of the inferior alveolar nerve or mental nerve branches.

The patient was transferred to the ward and observed for another 24 hours, during which the oral wound was monitored for signs of infection. She was seen by an immunologist to rule out an allergic reaction using the following immunological tests: antinuclear antibody, double-stranded deoxyribonucleic acid antibody, complement-3, complement-4, total immunoglobulin (Ig)E, Phadiatop (IgE against common

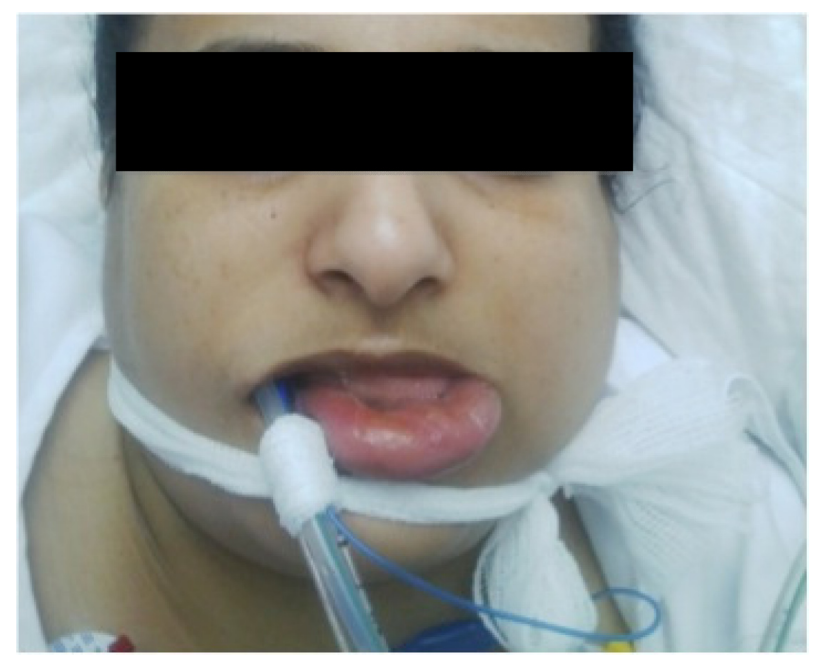

Figure 2 The edema spread to the sublingual and submental spaces and resulted in elevation of the tongue approximately 8 hours after the sodium hypochlorite accident. This required airway protection through oral intubation and mechanical ventilation. 


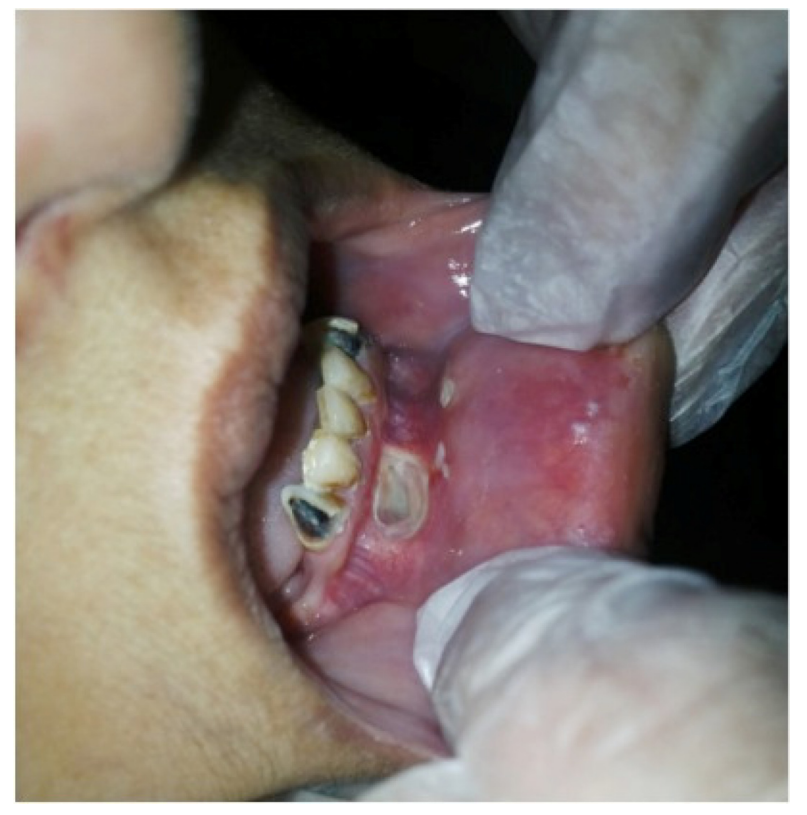

Figure 3 A deep ulcer developed in the lower anterior buccal vestibule, in close proximity to the tooth being treated.

inhalant allergens), thyroid peroxidase antibody, thyroid thyroglobulin antibody, IgG, IgA, and IgM. All of the allergen tests were negative, and the antibodies were within the normal limits. A skin patch test was negative for $\mathrm{NaOCl}$ hypersensitivity.

The patient was discharged from the hospital on a short taper of prednisone. She continued to be followed up as an outpatient, and during this period, the intraoral wound was monitored. Healing of the ulcer occurred through secondary intention, and it completely healed without a significant scar or nerve deficit after approximately 3 weeks. The patient refused to return for completion of the planned dental treatment.

The differential diagnosis of the case includes an $\mathrm{NaOCl}$ accident and an allergic reaction to the rubber dam or $\mathrm{NaOCl}$. The patient did not exhibit the typical signs of an allergic reaction, such as itching or rash, and the allergic testing for $\mathrm{NaOCl}$ was negative. In addition, the needle used for irrigation was a regular needle, not an endodontic one, and the solution may have been applied under pressure, resulting in perforation into the apical region and extravasation into the tissue. Therefore, a diagnosis of $\mathrm{NaOCl}$ accident was established.

\section{Discussion}

$\mathrm{NaOCl}$ is an effective irrigation solution, but it may cause serious complications such as the injection of $\mathrm{NaOCl}$ into the periapical tissue. ${ }^{6} \mathrm{NaOCl}$ has a cytotoxic effect when it comes in contact with vital tissue, because it causes hemolysis and ulceration, inhibits neutrophil migration, and damages endothelial and fibroblast cells. ${ }^{7}$

The expression of $\mathrm{NaOCl}$ beyond the confines of the root canal and its subsequent consequences are known as a hypochlorite accident, as was first reported by Becker et al ${ }^{8}$ in 1974. Despite the use of a rubber dam, a hypochlorite accident may occur due to unfamiliarity with the use of $\mathrm{NaOCl}$, such as the improper placement or faulty positioning of the clamps and frames. ${ }^{9}$ Additionally, complications such as injection into the maxillary sinuses, seepage through the lateral root perforations, accidental injection instead of an anesthetic solution, and splashing into the eyes have been reported. ${ }^{10,11}$ Few reports regarding hypersensitivity and allergic reactions caused by the application of $\mathrm{NaOCl}$ are presented in the dental literature.

To the best of our knowledge, the life-threatening tissue space edema secondary to an $\mathrm{NaOCl}$ accident has only been reported once by Bowden et $\mathrm{al}^{12}$ in 2006. In their case report, steroids were used because of the rapidly arising tissue edema, the steroid efficacy in these situations, and the anti-inflammatory properties of this group of drugs.

Extrusion of the $\mathrm{NaOCl}$ beyond the root apex during root canal treatment is a rare complication, but if it occurs, it causes chemical burns and tissue necrosis. Protective measures include the provision of a protective bib impermeable to liquid, which protects the patient's clothes; protective glasses for the clinical team as well as the patient; proper use of a rubber dam and a side-venting needle and syringe for canal irrigation, ie, using only Luer-Lok style syringes and needles that are loosely positioned in the canal; and the careful control of irrigant delivery and exposure to $\mathrm{NaOCl} .{ }^{13}$ Deep delivery into the periapical tissue can be prevented by use of a coronal access cavity. ${ }^{3}$ Additionally, the search for a new safer and effective irrigating solution is important to avoid the possibility of a life-threatening situation such as the one presented in this manuscript.

Kleier et a $1^{14}$ suggested that females are more subject to this complication than males because of their decreased bone thickness and density. These researchers suggested that $\mathrm{NaOCl}$ accidents may be caused when $\mathrm{NaOCl}$ has direct access to a soft-tissue space, such as the buccal or infraorbital space, rather than simply contacting periapical tissue, as occurs when the anatomic apex of a tooth naturally fenestrates through the overlying alveolar bone or when the alveolar bone has been perforated by a disease process, leading to a fenestration of the overlying bone. 
In the case presented in this manuscript, tissue decompression was not required, due to the early detection and management, the use of immediate intravenous steroids, and referral to the ICU, whereas in the case reported by Bowden et al, ${ }^{12} 8$ hours elapsed from the time of the incident to the time of referral.

Clinicians should always bear in mind the potential risks associated with the use of $\mathrm{NaOCl}$ and should take the proper precautions to prevent any possible complications. Early detection and management are key factors in the prognosis and outcome of a case such as the one presented in this manuscript.

\section{Consent}

Written informed consent was obtained from the patient for the publication of this case report and any accompanying images. A copy of the written consent is available for review from the editor of this journal.

\section{Disclosure}

The authors do not have any financial or nonfinancial competing interests to disclose.

\section{References}

1. Spangberg L. Instruments, materials and devices. In: Cohen S, Burns R, editors. Pathways of the Pulp. 8th ed. St Louis, MO: Mosby; 2002: 544-546.
2. Abou-Rass M, Piccinino MV. The effectiveness of four clinical irrigation methods on the removal of root canal debris. Oral Surg Oral Med Oral Pathol. 1982;54(3):323-328.

3. Brown DC, Moore BK, Brown CE Jr, Newton CW. An in vitro study of apical extrusion of sodium hypochlorite during endodontic canal preparation. J Endod. 1995;21(12):587-591.

4. Hulsmann M, Hahn W. Complications during root canal irrigation literature review and case reports. Int Endod J. 2000;33(3):186-193.

5. Sabala CL, Powell SE. Sodium hypochlorite injection into periapical tissues. J Endod. 1989;15(10):490-492.

6. Becking AG. Complications in the use of sodium hypochlorite during endodontic treatment. Report of three cases. Oral Surg Oral Med Oral Pathol. 1991;71(3):346-348.

7. Gatot A, Arbelle J, Leiberman A, Yanai-Inbar I. Effects of sodium hypochlorite on soft tissues after its inadvertent injection beyond the root apex. J Endod. 1991;17(11):573-574.

8. Becker GL, Cohen S, Borer R. The sequelae of accidentally injecting sodium hypochlorite beyond the root apex. Report of a case. Oral Surg Oral Med Oral Pathol. 1974;38(4):633-638.

9. Serper A, Ozbek M, Calt S. Accidental sodium hypochlorite-induced skin injury during endodontic treatment. J Endod. 2004;30(3):180-181.

10. Herrmann J, Heicht R. Complications in therapeutic use of sodium hypochlorite. J Endod. 1979;5:160-163.

11. Ehrich DG, Brian JD Jr, Walker WA. Sodium hypochlorite accident: inadvertent injection into the maxillary sinus. J Endod. 1993;19(4): 180-182.

12. Bowden JR, Ethunandan M, Brennan PA. Life-threatening airway obstruction secondary to hypochlorite extrusion during root canal treatment. Oral Surg Oral Med Oral Pathol Oral Radiol Endod. 2006;101(3):402-404.

13. Spencer HR, Ike V, Brennan PA. Review: the use of sodium hypochlorite in endodontics - potential complications and their management. Br Dent J. 2007;202(9):555-559.

14. Kleier DJ, Averbach RE, Mehdipour O. The sodium hypochlorite accident: experience of diplomates of the American Board of Endodontics. J Endod. 2008;34(11):1346-1350.
Clinical, Cosmetic and Investigational Dentistry

\section{Publish your work in this journal}

Clinical, Cosmetic and Investigational Dentistry is an international, peer-reviewed, open access, online journal focusing on the latest clinical and experimental research in dentistry with specific emphasis on cosmetic interventions. Innovative developments in dental materials, techniques and devices that improve outcomes and patient satisfaction

\section{Dovepress}

and preference will be highlighted. The manuscript management system is completely online and includes a very quick and fair peerreview system, which is all easy to use. Visit http://www.dovepress. com/testimonials.php to read real quotes from published authors. 